\title{
PENCEGAHAN KARIES GIGI MELALUI APLIKASI FLUORIDE VARNISH TERHADAP MURID SD ISLAM TELADAN AL HIDAYAH
}

\author{
Vitri Nurilawaty $^{1}$, Rahaju Budiarti $^{2}$, Erwin $^{3 \bowtie}$, Tedi Purnama ${ }^{4}$ \\ Coreponding author: erwin7tgm@gmail.com \\ 1,2,3,4 Jurusan Keperawatan Gigi, Poltekkes Kemenkes Jakarta I, Indonesia
}

Genesis Naskah: Submitted: 18-10-2021, Revised: 26-10-2021, Accepted: 02-11-2021

\begin{abstract}
Abstrak
Murid masa usia sekolah dasar merupakan kelompok resiko tinggi kerusakan gigi oleh karena karies salah satunya karena faktor perilaku anak yang secara umum belum paham cara pemeliharaan kesehatan gigi yang baik, sekolah dasar sebaiknya memiliki program yang pemeliharan kesehatan gigi salah satunya adalah pencegahan karies gigi pada murid. Tujuan kegiatan pengabdian masyarakat adalah melakukan upaya pencegahan karies gigi dengan aplikasi fluoride varnish terhadap murid kelas I \& II SD Islam teladan Al Hidayah. Sasaran mitra kegiatan pengabdian masyarakat adalah kepala sekolah, orangtua dan murid-murid kelas 1 \& II Sekolah dasar Islam Teladan Al Hidayah. Bentuk kegiatan pengabmas yaitu dengan melakukan advokasi, penyuluhan pencegahan karies gigi dan aplikasi fluoride varnish. Hasil kegiatan memberikan dampak yaitu terlaksana nya kegiatan advokasi, penyuluhan dan praktek aplikasi pengolesan fluoride varnish dengan baik, meningkatnya pengetahuan dan keterampilan orang tua dalam upaya pencegahan karies gigi kepada anaknya. Kesimpulan terlaksananya dengan baik rangkaian kegiatan upaya pencegahan karies gigi dengan aplikasi fluoride varnish terhadap murid kelas I \& II SD Islam teladan Al Hidayah.
\end{abstract}

Kata Kunci: Pencegahan Karies Gigi, Fluoride Varnish, Murid

\section{PREVENTION OF DENTAL CARRIES THROUGH FLUORIDE VARNISH} APPLICATION FOR STUDENTS OF SD ISLAM TELADAN AL HIDAYAH

\begin{abstract}
Elementary school-age students are a high-risk group for tooth decay due to caries, one of which is because children's behavior, in general, does not understand how to maintain good dental health, elementary schools should have programs that maintain dental health, one of which is the prevention of dental caries in students. The purpose of community service activities is to make efforts to prevent dental caries by applying fluoride varnish to grade I \& II students of Al Hidayah Islamic Elementary School. The target community service partners are the principal, parents, and grade 1 \& II students of the Islamic Elementary School Teladan Al Hidayah. The forms of community service activities are advocacy, counseling on the prevention of dental caries, and the application of fluoride varnish. The results of the activity have an impact on the implementation of advocacy, counseling, and good practice of applying fluoride varnish, activities, and skills of parents to prevent dental caries for their children. The conclusion is that a series of efforts to prevent dental caries has been carried out with the application of fluoride varnish for grade I \& II students of Al Hidayah Islamic Elementary School.
\end{abstract}

Keywords: Prevention Of Dental Carries, Fluoride Varnish, Student 


\section{Pendahuluan}

Masa usia anak-anak merupakan masa penting untuk perkembangan tubuh dan kesehatannya. Status kesehatan yang terjaga sedari dini akan memperbesar potensi lahirnya generasi yang sehat, cerdas dan kuat yang akan melanjutkan pembangunan bangsa di masa depan, tidak terkecuali kesehatan gigi dan mulut. Dalam ilmu Kesehatan gigi masa usia anak sekolah dasar adalah periode gigi bercampur yang artinya didalam rongga mulutnya gigi susu yang masih ada akan mulai digantikan oleh gigi permanen secara bertahap sampai habis semua gigi susu tersebut (Prisinda et al., 2017).

Murid masa usia sekolah dasar merupakan kelompok resiko tinggi kerusakan gigi oleh karena karies salah satunya karena faktor perilaku anak (Erwin et al., 2021). Kelompok umur tersebut yang secara umum belum paham cara pemeliharaan kesehatan gigi yang baik ditambah kesukaan anak mengkonsumsi jajanan/makanan kariogenik yang manis dan melekat (Winahyu et al., 2019).

Praktisi kesehatan gigi menggolongkan kelompok umur anak sekolah dasar merupakan salah satu kelompok rentan yang butuh perhatian lebih pada kesehatan gigi dan mulutnya, kesalahan yang banyak ditemukan selain karena perilaku pemeliharan gigi geligi anak yang masih buruk juga karena periode ini seringkali anak, orang tua dan guru lalai tidak mengetahui atau tidak mengenali masalah yang timbul pada gigigeligi anak, seringkali gigi yang rusak periode itu tidak diupayakan untuk dilakukan pencegahan atau penanganan primer. Ironisnya keadaan gigi yang terlanjur rusak tidak akan bisa membaik dengan sendirinya, karena dibutuhkan perawatan medis gigi pada akhirnya seperti penambalan gigi atau perawatan saluran akar yang berbiaya tidak murah, bahkan bisa tidak mungkin dilakukan pencabutan gigi sehingga membuat gigi anak menjadi cacat (ompong) keadaan ini adalah kerugian besar karena disamping akan bermasalah pada fungsi fisologisnya seperti pada pengunyahan, estetik, fonetik (pengucapan kata), dan hambatan dalam belajar, anak dengan gigi yang sudah bermasalah atau cacat (seperti ompong, berlubang, dll) akan memperkecil peluang kelulusannya untuk berkarir pada profesi-profesi tertentu seperti polisi, tentara, pilot, pramugari dan sejenisnya dimasa depan.

Peraturan Menteri Kesehatan No 89 tahun 2015 menyatakan salah satu program kesehatan yang wajib dilakukan pemerintah di sekolah adalah UKGS (usaha Kesehatan Gigi Sekolah) yang terintegrasi dengan kegiatan UKS (Usaha Kesahatan Sekolah) dan yang harus dijalankan Oleh karena itu bagi Sekolah Dasar harus memiliki program yang terkait kesehatan gigi, minimal ada upaya promotif (peningkatan kesehatan) dan preventif (pencegahan penyakit) sebagai pelayanan kesehatan gigi primer yang bisa dilakukan di sekolah.

Upaya promotif dan preventif adalah upaya dasar dalam pelayanan kesehatan yang bertujuan meningkatkan derajat kesehatan dan mencegah dari terjadinya penyakit dalam hal ini penyakit gigi dan mulut pada anak-anak. Bentuk kegiatan minimal yang dapat dijalankan secara rutin dilingkungan sekolah antara lain seperti 
dental health education/DHE (Penyuluhan kesehatan gigi), sikat gigi massal, termaksud pengolesan fluor pada gigi (Kemenkes, 2012). Salah satu cara pemberian fluor yaitu melalui bahan fluoride varnish.

Mitra pengabmas adalah SD Islam Teladan Al Hidayah yang beralamat di Cilandak Timur, Jakarta Selatan. Observasi dan wawancara langsung menunjukkan sekolah tersebut telah ada unit UKS nya dalam lingkungan sekolah tetapi progam kesehatan giginya bwlum berjalan optimal, khususnya program pencegahan karies pada murid sekolah tersebut. Keadaan pandemic covid-19 membuat program kesehatan gigi sekolah menjadi semakin terbatas. Oleh karena itu kami bekerjasama dengan pihak sekolah untuk melakukan kegiatan pengabdian masyarakat dengan judul pencegahan karies gigi dengan aplikasi fluoride varnish terhadap murid kelas I \& II SD Islam teladan Al Hidayah.

Tujuan kegiatan pengabdian masyarakat adalah melakukan upaya pencegahan karies gigi dengan aplikasi fluoride varnish terhadap murid kelas I \& II SD Islam teladan Al Hidayah

\section{Metode Pelaksanaan}

Periode kegiatan berlangsung selama Juni sampai September 2021. Mitra sasaran adalah Kepala sekolah, murid-murid kelas I \& II dan orangtua murid kelas I \& II SD Islam Alhidayah. Metode intervensi pengabdian masyarakat dilakukan dengan metode-metode; advokasi, penyuluhan dan praktek aplikasi fluoride varnish.

Advokasi pada pengelola sekolah dilakukan tim pengabmas melakukan pendekatan persuasive untuk memberikan informasi kepada kepala Sekolah pentingnya program pencegahan karies gigi untuk murid kelas I \& II dengan fluoride varnish. kegiatan dilakukan dengan tahapan tim menjalin komunikasi nonformal kepada kepala sekolah, mengirimkan surat permohonan resmi kegiatan pengabmas, menjadwalkan pertemuan bersama kepala sekolah, dan melakukan dialog atau Focus Group Discussion (FGD) bersama kepala sekolah.

Penyuluhan pencegahan karies gigi dilakukan secara online dengan video conference, sasaran penyuluhan adalah orangtua dan murid kelas I \& II SD Islam teladan Al Hidayah. Materi yang diberikan dengan cara ceramah disertai pemutaran video pemeliharaan kesehatan gigi dan diakhiri dengan diskusi interaktif.

Praktek aplikasi fluoride varnish dilakukan modifikasi sebagai bentuk penerapan protokol kesehatan pencegahan covid-19, pendampingan dan praktek dilakukan secara daring juga merupakan modifikasi metode kegiatan sebagai bentuk protokol kesehatan pencegahan covid-19. Tim pengabmas mengoptimalkan proses pendampingan dengan cara :

1. Pengiriman pakat alat dan bahan praktek pengolesan fluoride varsnih kepada alamat rumah sasaran (orangtua dan murid)

2. Menyusun dan mengirimkan buku panduan cara pengolesan bahan fluoride varnish yang materinya disusun dengan penjelasan yang mudah dipahami serta gambar petunjuk langkah-langkah pengolesan

3. Membentuk whatss app group kecil antara tim pendamping dengan orangtua murid 
sehingga memudahkan koordinasi, pengarahan dan konsultasi setiap saat

4. Melakukan video conference daring terjadwal antara orangtua dengan tim pengabmas pendamping, sehingga bisa mengarahkan secara langsung cara pengolesan bahan pada gigi anak.

\section{Hasil dan Pembahasan}

\section{Advokasi}

Pelaksanaan kegiatan pengabdian kepada masyakarat yaitu advokasi kepada kepala sekolah SD Islam Alhidayah $1 \& 2$, kegiatan dilakukan sepanjang bulan mei sampai dengan bulan juni tahun 2021.

Tim pengabmas melakukan pertemuan dengan Kepala Sekolah SD Islam Al Hidayah I pada tanggal 8 juni tahun 2021 di ruang kepala sekolah SD Islam Al Hidayah I dan pertemuan dengan Kepala Sekolah SD Islam Al Hidayah 2 pada tanggal 13 juni tahun 2021 di ruang kepala sekolah SD Islam Al Hidayah 2, agenda kegiatan pada dua pertemuan tersebut adalah Focus Group Discussion untuk memberikan informasi pentingnya program pencegahan karies kepada murid kelas I \& II. Respon positif dan persetujuan ditunjukkan kedua kepala sekolah yang sangat menyambut baik manfaat kegiatan, Kepala Sekolah meminta tim pengabmas membuat rancangan prosedur pelaksanaan kegiatan secara aman untuk diterapkan di masa pandemic covid-19.

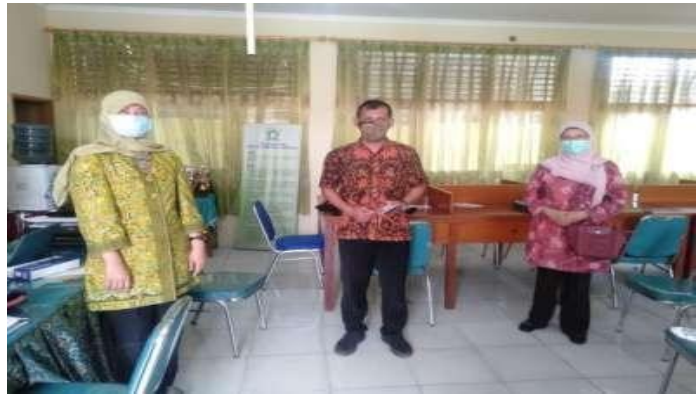

Gambar 1. Kegiatan advokasi tim pengabmas dengan Kepala Sekolah SD Islam Alhidayah

Advokasi kepada pimpinan mitra pengabmas merupakan tahapan awal pelaksanaan kegiatan. Proses ini merupakan langkah penting untuk memberikan pemahaman kepada pimpinan sekolah tentang pentingnya upaya pencegahan karies gigi pada murid kelas I \& II, tim memberikan penjelasan keadaan klinis dan aspek perilaku kelompok sasaran murid kelas I \& II yang merupakan kelompok beresiko tinggi dengan kejadian karies gigi, apalagi selama pandemic covid-19 mengakibatkan program kesehatan yang umumnya terlaksana langsung di sekolah melalui kegiatan UKGS dari Puskemas menjadi tertunda sehingga tidak dapat optimal memberikan program pencegahan karies gigi pada kelompok tersebut. Orangtua yang menjadi pengawas anak dirumah juga belum tentu sepenuhnya tepat melakukan upaya pencegahan dari resiko kerusakan pada gigi geligi anak dengan baik, faktor keterbatasan informasi dan keterbatasan bahan preventif kesehatan gigi yang rutin bisa digunakan dirumah menjadi kendala orangtua dalam melakukan pengawasan kesehatan gigi anak.

Advokasi diharapkan akan membentuk persepsi Kepala Sekolah untuk mendukung dan menerapakan upaya intrevensi pencegahan karies 
gigi agar dimulai sejak dini kepada murid-murid di lingkungan sekolahnya. Kepala sekolah dapat membuat kebijakan untuk menerapkan program tersebut kepada murid-muridnya sekaligus menjadi mediator untuk memberikan edukasi dan pemahaman kepada orangtua murid, harapannya upaya kesehatan tersebut akan terlaksana berkelanjutan baik dilingkungan sekolah maupun ketika anak berada di rumah.

Pelaksanaan kegiatan pengabmas yang berlangsung dimasa pandemic covid-19 mengharuskan proses persiapan, pelaksaanaan dan evaluasi kegiatan dilakukan dengan menerapkan protokol kesehatan secara ketat sehingga kegiatan focus group discussion dalam advokasi sangat bermanfaat bagi tim pengabmas dan mitra sasaran untuk mempersipkan pelaksanaan tahapan-tahapan kegiatan lanjutan yang direncanakan.

Tim pengabmas dapat melakukan identifikasi awal suasana mitra sasaran yang akan diberikan intervensi, bagaimana proses pembelajaran tatap muka dan daring yang sedang berlangsung, berdiskusi alternative modifikasi metode kegiatan, jumlah sasaran kelas I \& II, dan hal non teknis lain yang berkaitan dengan pelaksanaan kegiatan. Sedangkan bagi mitra sasaran akan mempersiapkan diri untuk mengatur jadwal kegiatan secara tepat diantara jadwal pembelajaran, mempersiapkan dan mensosialisasikan program kepada orangtua dan murid sasaran, serta persiapan lainnya yang berkaitan dengan pelaksanaan kegiatan.

2. Penyuluhan pencegahan karies gigi

Kegiatan penyuluhan dengan tema pencegahan karies gigi pada anak dapat terlaksana dengan baik pada hari selasa tanggal 10 Agustus 2021, proses penyuluhan dilakukan secara daring melalui kanal zoom meeting dengan sasaran yaitu murid kelas $1 \& 2$ yang didampingi oleh orangtua murid masing-masing. Proses penyuluhan berlangsung selama 90 menit dengan schedule kegiatan yaitu perkenalan diri tim pengabmas, penjelasan rangkaian kegiatan, serta penyuluhan dan tanya jawab.

Jalannya kegiatan penyuluhan terlaksana dengan lancar dan sasaran penyuluhan menunjukkan antusisme mengikuti kegiatan. Sasaran yang mengikuti kegiatan terdata berjumlah 57 peserta zoom, orangtua murid yang hadir banyak yang memberikan pertanyaan terkait materi yang diberikan.
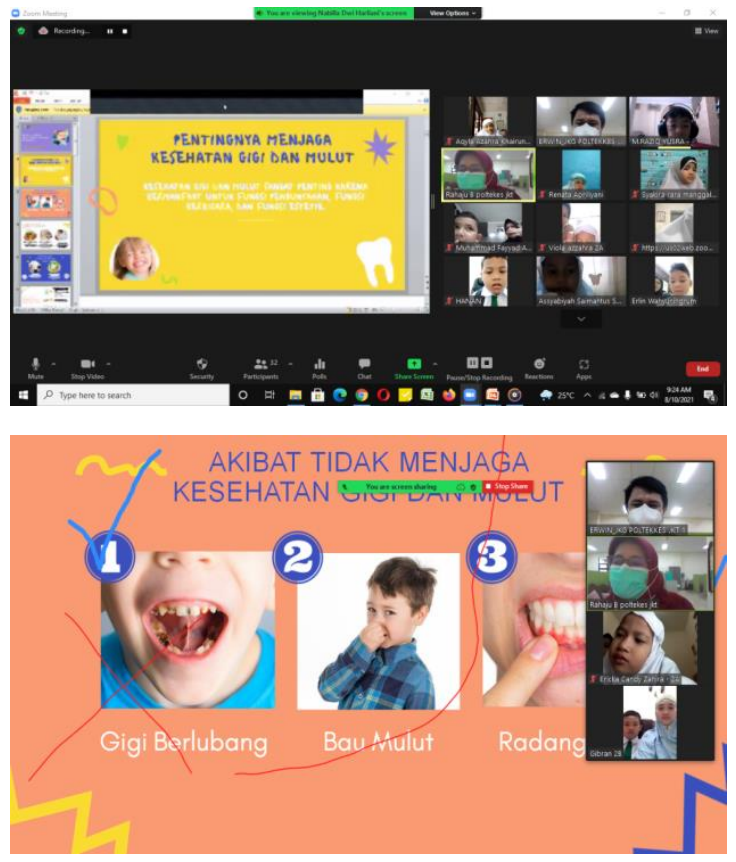

Gambar 2. Kegiatan penyuluhan secara daring

Dalam kegiatan penyuluhan dilakukan evaluasi yaitu pre dan post test pemahaman orang tua murid tentang upaya pencegahan lubang gigi (karies) pada anak, tim pengabmas memberikan 
kuisioner berisi pertanyaan-pertanyaan melalui media google form, hasil diperoleh sebagai berikut :

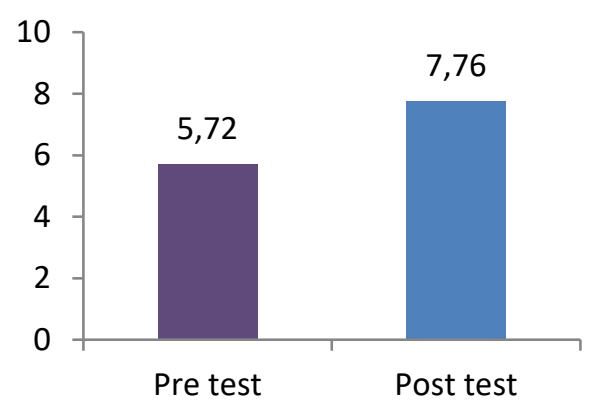

Gambar 3. Grafik nilai rata-rata pre \& post test pengetahuan orangtua murid

Kuesioner bernilai maksimal 10 poin, diketahui nilai rata-rata pre test orangtua murid sebesar 5,72 dan setelah diberikan penyuluhan terjadi peningkatan nilai rata-rata post test orangtua murid sebesar 7,76. Dalam proses penyuluhan peserta menunjukkan antusiasme yang baik untuk mengikuti kegiatan, peserta banyak menanyakan masalah kesehatan gigi dialami anak dan bagaimana pencegahannya.

Hasil evaluasi menunjukkan ketertarikan peserta dengan topik penyuluhan dan efektifitas kegiatan meningkatkan pemahaman orangtua. Kegiatan dilakukan secara daring sebagai metode penyesuaian terhadap kondisi pandemi covid-19 yang masih melanda. Orangtua dan murid masih menjalani pembelajaran secara daring dari rumah masing-masing oleh karena itu sebagai upaya pelayanan kesehatan juga harus secara adaptif mencarikan solusi agar tetap menjangkau masyarakat pada kondisi seperti ini, salah satunya melalui penyuluhan kesehatan gigi dengan teknologi video conference secara daring.

Kegiatan dapat terlaksana dengan baik menunjukkan bahwa layanan kesehatan gigi dapat terlaksana kepada masyarakat meskipun dalam kondisi pandemic covid-19 yang tidak memungkinkan pertemuan secara langsung. Dalam hal ini upaya promotif kesehatan adalah kegiatan yang sangat memungkinkan dapat terlaksana secara online dengan optimal bahkan akan menjadi menarik karena akan merangsang peserta terlibat aktif dalam kegiatan penyuluhan daring. Dalam penyuluhan secara online tim pengabmas menyajikan informasi melalui powerpoint yang menarik serta video animasi pemeliharaan kesehatan gigi untuk anak. Penggunaan fitur-fitur audio-visual pada media penyuluhan menjadi daya tarik bagi peserta untuk mendengarkan dan menyaksikan informasi yang diberikan, hal tersebut akan sangat membantu petugas yang memberikan penyuluhan untuk menyampaikan informasi secara interaktif dan mudah dipahami oleh peserta.

Menurut Martahayu \& Yunita (2021) menjelaskan hasil kegiatan penyuluhan kesehatan yang dilakukan menggunakan media berbasis audio-visual sangat banyak manfaatnya, penggunaan media mampu menarik perhatian peserta sehingga penyampaian informasi kesehatan yang diberikan akan efektif diterima, peserta akan mampu merasakan, melihat dan memberikan gambaran nyata tentang informasi tersebut sehingga realitas materi mampu memberikan pengalaman nyata pada peserta.

3. Praktek aplikasi fluoride varnish

Proses kegiatan aplikasi fluoride varnish dapat terlaksana selama rentang tanggal 12 Agustus sampai dengan tanggal 12 september 
2021. Modifikasi metode dilakukan tim pengabmas sebagai bentuk adaptasi dalam rangka penerapan protokol kesehatan pencegahan kasus covid-19.

Sasaran yang mengkuti praktek berjumlah 67 orang. Praktek pengolesan fluoride varnish oleh orangtua murid kepada anaknya dilakukan secara langsung dibawah pembimbingan dan pengarahan oleh oleh pendamping anggota tim pengabmas secara daring melalui video conference, setiap angggota tim pengabmas menjadwalkan melalui perjanjian dengan orangtua murid untuk menentukan jadwal pertemuan video conference.
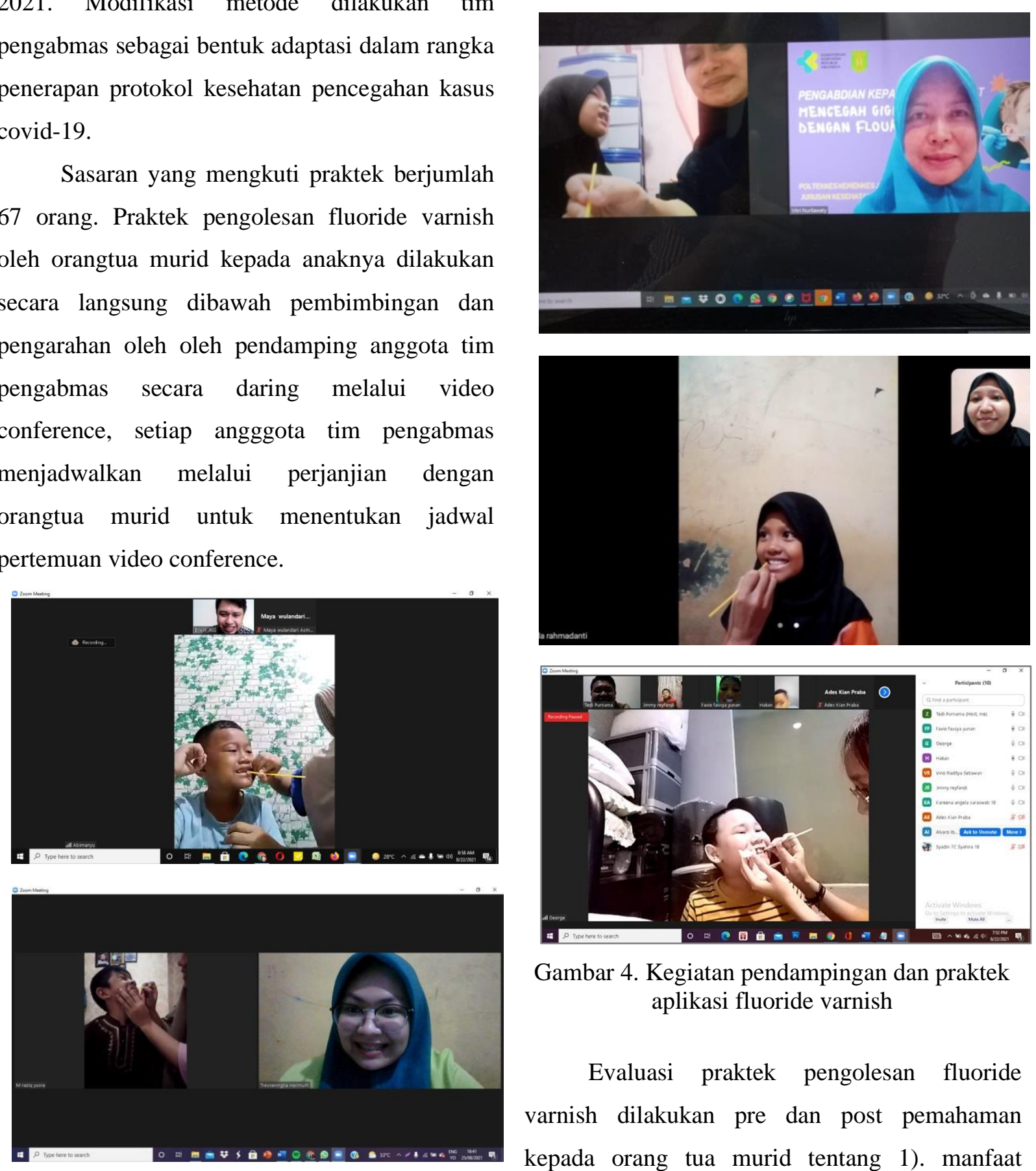

Gambar 4. Kegiatan pendampingan dan praktek aplikasi fluoride varnish

Evaluasi praktek pengolesan fluoride varnish dilakukan pre dan post pemahaman kepada orang tua murid tentang 1). manfaat

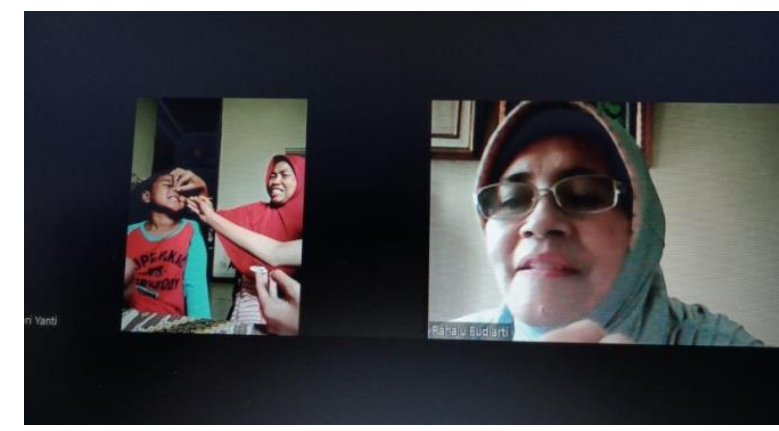

fluoride varnish, dan 2). cara pengolesan fluoride varnish pada gigi anak. Tim pengabmas memberikan survey tersebut melalui media google form, hasil diperoleh sebagai berikut : 


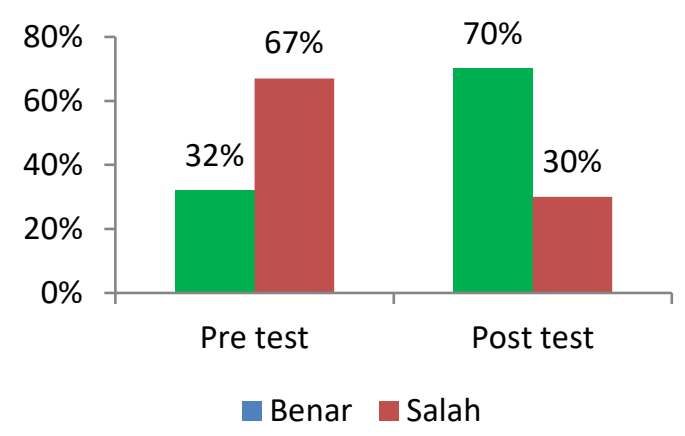

Gambar 5. Grafik kategori pemahaman orangtua murid tentang manfaat bahan fluoride varnish pre $\&$ post pendampingan praktek

Berdasarkan hasil evaluasi diketahui sebelum pendampingan mayoritas orangtua murid memiliki pemahaman yang salah tentang manfaat fluoride varnish yaitu sebesar 67\%, terjadi perubahan setelah pendampingan dimana mayoritas orangtua murid memiliki pemahaman yang benar tentang manfaat fluoride varnish yaitu sebesar $70 \%$.

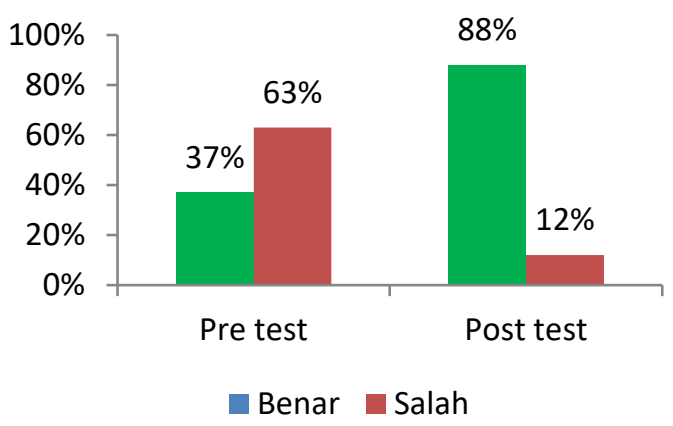

Gambar 6. Grafik kategori pemahaman orangtua murid tentang cara pengolesan fluoride varnish pre $\&$ post pendampingan praktek

Berdasarkan hasil evaluasi diketahui sebelum pendampingan mayoritas orangtua murid memiliki pemahaman yang salah cara pengolesan fluoride varnish yaitu sebesar 63\%, terjadi perubahan setelah pendampingan dimana mayoritas orangtua murid memiliki pemahaman yang benar cara pengolesan fluoride varnish yaitu sebesar $88 \%$.
Pengolesan bahan fluoride varnish merupakan tindakan preventif kesehatan gigi untuk memperkuat lapisan permukaan email yang dapat rusak karena proses demineralisasi oleh bakteri penyebab karies gigi, tindakan dilakukan dengan mengolesakan bahan fluor secara langsung pada permukaan topikal mahkota gigi. Bahan fluoride telah umum digunakan dalam pelayanan kesehatan oleh praktisi kesehatan gigi kepada pasien. Kandungan fluoride sering kita dapatkan dari makanan dan minuman yang kita konsumsi meskipun dalam jumlah yang sedikit, termaksud juga bahan fluoride akan kita temukan pada produk pasta gigi yang digunakan seharihari saat menyikat gigi.

Pengolesan fluoride varnish bertujuan memberikan efek yang lebih maksimal dalam perlindungan lapisan email gigi karena proses penyerapannya yang lebih mudah. Menurut Jagan (dalam Susi Indriaswati, 2019) aplikasi bahan fluoride dengan pengolesan langsung pada permukaan gigi akan memberikan keuntungan yaitu kesempatan fluoride untuk masuk dan terserap dengan baik pada email, kemudian ion hidroksil yang telah hilang dari email akan digantikan oleh ion fluoride sehingga email gigi akan memiliki ketahanan dari serangan asam karena proses karies gigi. Fluoride varnish direkomendasikan aplikasinya karena cara penggunaannya yang mudah, sederhana, dan dapat diterima baik oleh pasien anak.

Anak usia sekolah dasar adalah kelompok rentan kasus kerusakan gigi sehingga tindakan preventif harus dilakukan secara intensif pada kelompok usia tersebut. Keadaan pandemi covid- 
19 menjadikan keterbatasan pada akses layanan kesehatan yang bisa diberikan secara langsung kepada murid baik melalui fasilitas layanan kesehatan ataupun intervensi di sekolah (seperti kegiatan UKGS). Sehingga sebagai alternative kegiatan tahapan pengabmas dilakukan modifikasi dengan mendorong dan melatih orangtua untuk ikut serta aktif melakukan upaya preventif melalui praktek pengolesan fluoride varnish pada anak masing-masing.

Dalam proses pendampingan orangtua dengan aktif berkonsultasi tentang bahan yang diberikan dan cara penggunaanya, pada praktek keterampilan pengolesan mandiri tim pengabmas memandu dan mengawasi prosedur yang dilakukan oleh orangtua melalui video conference, menunjukkan hasil seluruh sasaran yang terlibat aktif terlibat menunjukkan praktek aplikasi bahan secara tepat dihadapan tim pengabmas. Peningkatan pemahaman dan keterampilan orangtua yang ditunjukkan dengan tepat memberikan gambaran sasaran yang telah memahami kemanfaatan dan cara penggunaan fluoride varnish sebagai salah satu sumber bahan fluoride, sehingga dapat disimpulkan jika intervensi pendampingan yang dilakukan tim pengabmas dengan intensif mampu mendorong orangtua murid menjadi paham dan terlatih menggunakan bahan fluoride varnish secara mandiri sebagai upaya preventif kesehatan gigi pada anak dirumah karena kondisi pandemi covid-19 yang masih melanda

\section{Kesimpulan dan Saran}

Kesimpulan

Berdasarkanhasil dan pembahasan dapat ditarik kesimpulan yaitu terlaksananya dengan baik rangkaian kegiatan upaya pencegahan karies gigi dengan aplikasi fluoride varnish terhadap murid kelas I \& II SD Islam teladan Al Hidayah yang ditunjukkan dengan pengelola sekolah yang ikut mendorong dan memfasilitasi terlaksanannya program tersebut pada sasaran, penyuluhan yang efektif yang ditunjukkan dengan keikutsertaan peserta serta nilai rata-rata pengetahuan orangtua peserta yang meningkat setelah penyuluhan diberikan, dan aplikasi fluoride varnish pada murid secara baik dan efektif yang ditunjukkan dengan keterlibatan aktif orangtua peserta serta pemahaman dan keterampilan orangtua yang menjadi benar setelah dilakukan pendampingan dan praktek.

Saran

Berdasarakan kesimpulan dapat diberikan saran yaitu 1) intervensi kesehatan di sekolah harus dilakukan dengan persetujuan dan kerjasama yang baik dengan pengambil kebijakan 2) pemberian informasi melalui penyuluhan kesehatan gigi untuk anak secara efektif sebaiknya melibatkan keikutsertaan orangtua agar anak mendapatkan pemeliharaan dan pengawasan secara baik juga saat dirumah, 3) Pengenalan manfaat dan cara penggunaan fluoride akan mampu dipahami dan dapat diadopsi oleh orangtua dengan proses pendampingan yang intensif. 


\section{Daftar Pustaka}

Erwin, E., Fadjeri, I., Emini, E., Widiyastuti, R., Nurilawaty, V., \& Anggreni, E. (2021). Pendidikan Kesehatan Gigi Kepada Pramuka Siaga Kwartir Ranting Pasar Minggu: Dental Health Education For Standby Scout Of Pasar Minggu Quarter Branch. Gemakes Jurnal Pengabdian Kepada Masyarakat, 1(1), 7-13.

Indriaswati, S. (2019). Case Report Penggunaan Fluoride Varnish pada Kedokteran Gigi Anak. Bali: Fakultas Kedokteran Universitas Udayana.

Kemenkes, R. (2015). Permenkes No 89 tahun 2015 tentang Upaya Kesehatan Gigi dan Mulut. Jakarta: Kementerian Kesehatan Republik Indonesia.

Kemenkes, R. I. (2012). Pedoman Usaha Kesehatan Gigi Sekolah (UKGS). Jakarta: Kementerian Kesehatan RI.

Martahayu, V., \& Yunita. (2021). Penyuluhan Kesehatan Di Masa Pandemi Dan New Normal. Jurnal Pengabdian Masyarakat, 4(April), 6-10.

Prisinda, D., Wahyuni, I. S., Andisetyanto, P., \& Zenab, Y. (2017). Karakteristik karies periode gigi campuran pada anak usia 6-7 tahun. Padjadjaran Journal of Dental Researchers and Students, 1(2), 95-101.

Winahyu, K. M., Turmuzi, A., \& Hakim, F. (2019). Hubungan antara Konsumsi Makanan Kariogenik dan Risiko Kejadian Karies Gigi pada Anak Usia Sekolah di Kabupaten Tangerang. Faletehan Health Journal, 6(1), 2529. 